(C) [2008] IEEE. Reprinted, with permission, from [Chi-Chien Lin, David G. Dorrell and Min-Fu Hsieh, A Small Segmented Oscillating Water Column using a Savonius Rotor Turbine, ESustainable Energy Technologies, 2008. ICSET 2008. IEEE International Conference on, 24-27 Nov. 2008]. This material is posted here with permission of the IEEE. Such ermission of the IEEE does not in any way imply IEEE endorsement of any of the University of Technology, Sydney's products or services. Internal or personal use of this material is permitted. However, permission to reprint/republish this material for advertising or promotional purposes or for creating new collective works for resale or redistribution must be obtained from the IEEE by writing to pubs-permissions@ieee.org. By choosing to view this document, you agree to all provisions of the copyright laws protecting it 


\title{
A Small Segmented Oscillating Water Column using a Savonius Rotor Turbine
}

\author{
Chi-Chien Lin, David G. Dorrell, Senior Member, IEEE and Min-Fu Hsieh, Member, IEEE
}

\begin{abstract}
This paper outlines a project which addresses the use of a small segmented oscillating water column with three sections. The turbine utilises cascaded Savonius rotors (one for each section) and this system is developed and tested for validation of the performance algorithms. It is shown that the systems can be easily described and a system developed that can generate. It would be suitable for a shoreline location such as a harbour wall, where waves are random and not orthogonal to the column. Conversion rates in the region of $20 \%$ are tabulated for the system with an output of $25 \mathrm{~W}$ peak. The paper will give a full algorithm for the system while the digest outlines some crucial points with regards to the sizing and operation of the column with respect to the wave frequency and wavelength. The turbine is fully characterized - the generator is a brushless permanent magnet machine connected to a diode bridge rectifier and variable load.
\end{abstract}

Index Terms- Renewable energy, oscillating water column, Savonius rotor, performance.

\section{INTRODUCTION}

$\mathrm{T}_{\mathrm{in}}^{\mathrm{H}}$ HERE are several books that discuss the behavior of waves in terms of energy resource and their characteristics [1][2][3]. These often discuss the various wave energy devices that are in development. There has now been a rapid growth in the number of different devices that are being assessed for their viability. These are briefly described in [4].

The wave energy generation industry is still debating about the best design for producing electrical power from sea waves and in a recent count there were over 1000 patented ideas for wave energy conversion. They can be broken down into five basic technology groups [5]: oscillating water column (OWC); overtopping device; point absorbers (floating or mounted on the sea bed); surging devices; and mechanical extraction. This paper is concerned only with the oscillating water column. The normal arrangement for an oscillating water column (as studied here) utilizes a bi-directional air turbine. These can take the form of a Wells turbine or impulse turbine and these were extensively reviewed in [6]. This paper will introduce the use of a Savonius rotor into the oscillating water column as a possible alternative. This has already been studied in [7] and [8] and this paper takes the concept further, with more detailed measurements and algorithm development.

C.-C. Lin and M.-F. Hsieh. are with the Research Center of Ocean Environment and Technology, Department of System and Navel Mechatronic Engineering, National Cheng Kung University, Tainan 701, Taiwan (e-mail: chichien.lin@gmail.com and mfhsieh@mail.ncku.edu.tw).

D. G. Dorrell is with the Mechatronics and Intelligent Systems Group, Engineering, University of Technology, Sydney, NSW, Australia (e-mail: david.dorrell@uts.edu.au).

\section{The SEgmented Oscillating WATER COLUMN}

The general method of analysis is outlined here using the results of the theoretical turbine analysis of Hiramoto [9]. It is developed further here and a Savonius rotor is used as the turbine. This is a cost-effect rotor structure although the conversion factor is also low [10]. However, in smaller applications, a conversion rate of $15 \%$ may be more acceptable. The usual type of turbine used in an oscillating water column is the Wells turbine. This requires a high Reynold's number, and hence a larger size, to operate successfully; [11] illustrated this with a CFD study.

To explain the system properly, this section is arranged into three sub-sections. The first addresses the oscillating water column arrangement and the second describes the Savonius rotor. The third subsection considers the modification of the water height in each chamber.

\section{A. Oscillating water column}

Fig. 1 shows the segmented oscillating water column as used in this study. It has three chambers (although for a full sized arrangement there could be many more) which are $1.5 \mathrm{~m}$ wide and $0.5 \mathrm{~m}$ deep. Therefore the overall column area is 4.5 $\mathrm{m}$ by $0.5 \mathrm{~m}$. Fig. 2 shows a photograph of the column in the water with the turbines mounted on the top (as in [8]). The internal dividers funnel the air up to the three turbines. Waves travel across the face of the column so that the water level in each chamber will be different depending on the length of the waves. This issue was addressed in [11] when the chamber was used in conjunction with a Wells turbine where the three chambers were merged into one to supply air to one turbine. It is further investigated here with further modifications to the theory.

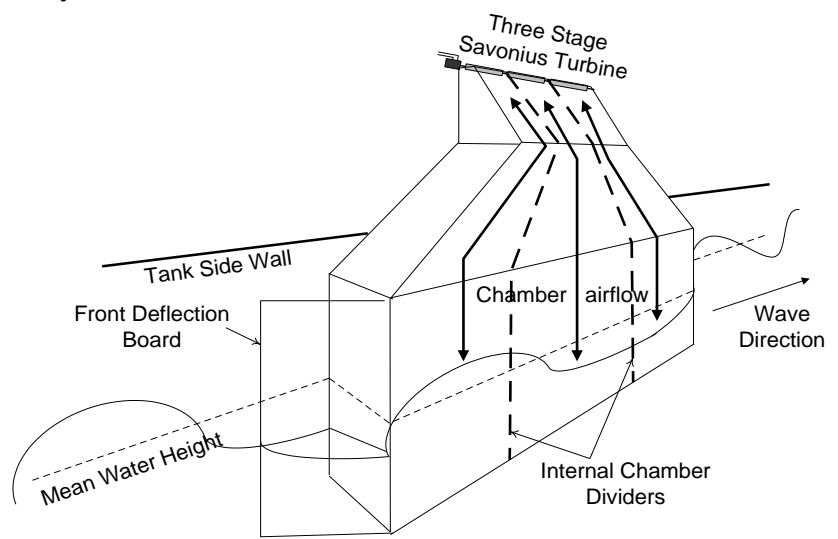

Fig. 1. Schematic showing arrangement of segmented column and three savonius rotors connected in series. 


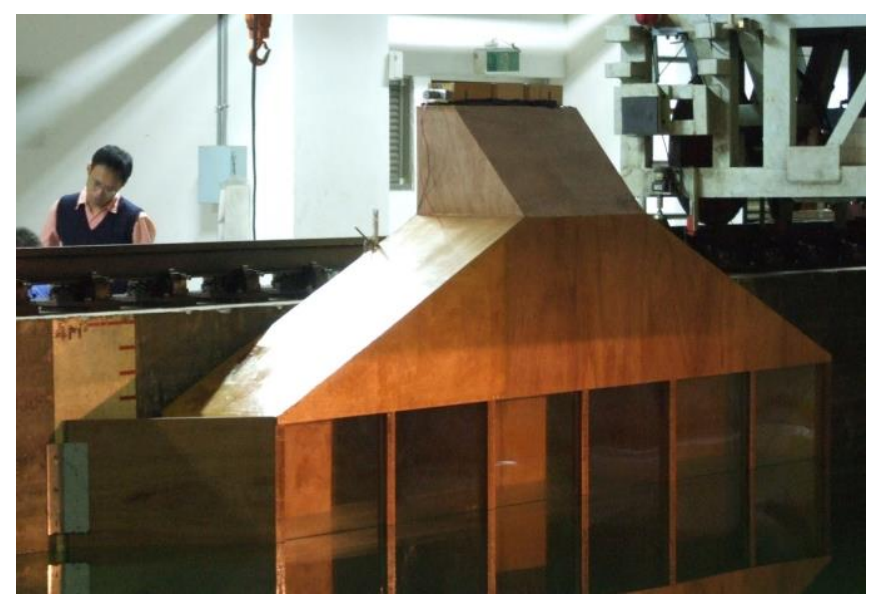

Fig. 2. Column in water with no turbine ducting (as used in [8]).

\section{B. Savonius rotor}

This arrangement was used in a previous study [8]. However, in [8], this was very much a proof-of-concept study using waves of limited height. The available power with the smaller waves was limited. One issue from the first study was the lack of turbine ductwork and this was added as illustrated in Fig. 3 (a) and (b). This appeared to improve the turbine performance considerably.

Each turbine was $280 \mathrm{~mm}$ long and $95 \mathrm{~mm}$ wide (one for each column segment) and these are connected mechanically in-line. In addition a slit was put under the center turbine so that an air-flow meter could be inserted as shown. While the use of a hot-wire anemometer would be ideal, these are not straight forward to implement, particularly when the airflow in oscillating as it is here. Therefore a simple arrangement was implemented using a fan type of meter as shown here. However, future work will be to instigate a hot-wire anemometer type of air-flow meter and to calibrate the air flow through the fan type of meter under oscillating air flow conditions.

To load the turbines then a brushless permanent-magnet machine was attached and the circuit shown in Fig. 3 (c) used. The electronic load is a resistive load so that the power delivered to the load could be easily measured. There will be friction and windage associated with the generator and we are concerned with the power available at the shaft of the turbine unit. Therefore the generator was characterised on a separate test rig before use so that the friction and windage over a wide speed range was known and could be factored in to the calculation of the turbine power.

Just to recap on the characteristics of a Savonius rotor, Fig. 4 shows the cross section of the turbine and for good operation the ration of $S / d$ should be about $20 \%$. Therefore for a cup diameter of $50 \mathrm{~mm}$ then the turbine diameter should be $95 \mathrm{~mm}$ (including cup thickness and duct clearance). The performance at very low tip speed ratio (blade tip speed divided by the airflow velocity), and also close to $X_{0}$, is often omitted from the performance studies and is therefore not clear. Percival et al [10] found that the maximum conversion factor was found to be 0.245 at a tip speed ratio of 0.95 and this appears to be a good value compared to most studies.

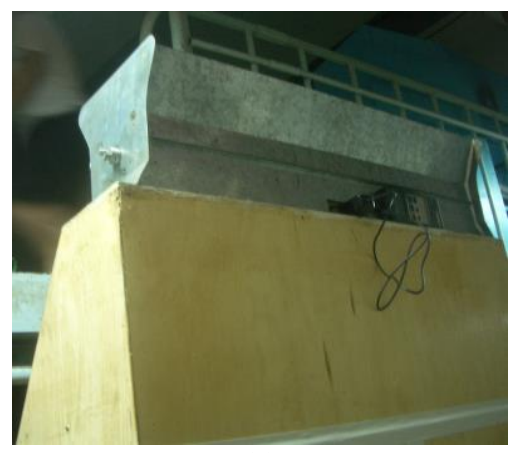

(a)

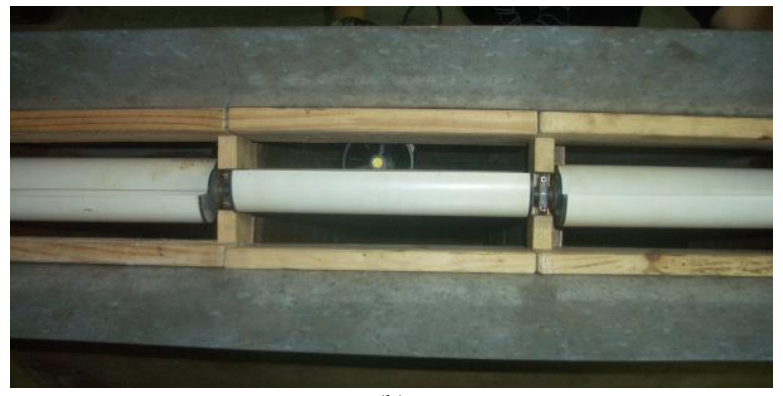

(b)

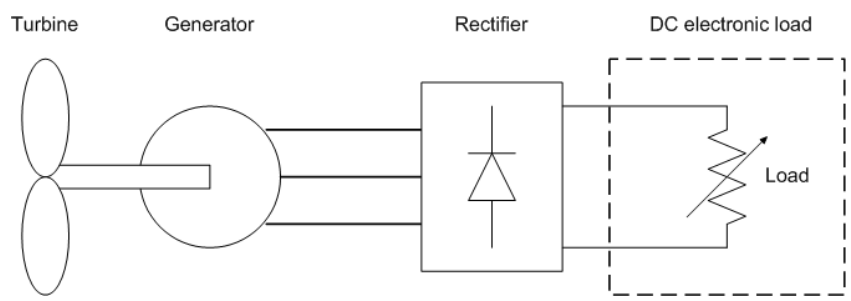

(c)

Fig. 3. Column and turbines with new ducting used in this study, (a) rear/side view showing flow meter under the center turbine, (b) top view and (c) circuit used for the turbine power delivery.
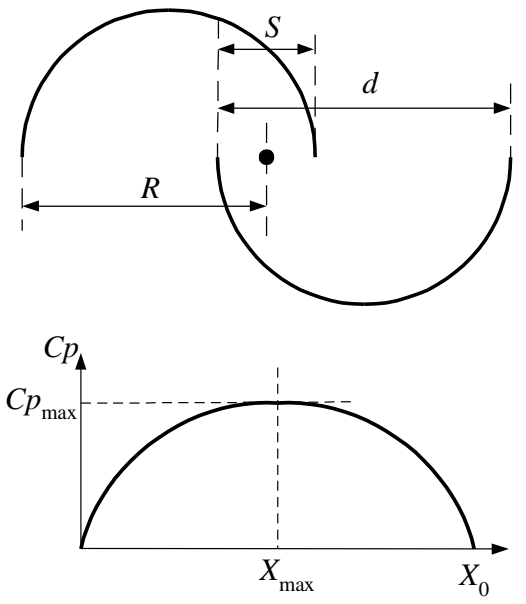

Tip Speed Ratio $X$

Fig. 4. Savonius rotor cross-section and tip speed ratio characteristic. 


\section{Chamber water height modification due to wavelength and calculation of turbine inlet velocity}

Fig. 5 gives a schematic of the oscillating water column and Fig. 6 illustrates the issues concerned with the calculation of the internal water height in the column. In [11] the water height in a water column, where the depth (as apposed to the width which faces the oncoming wave) approaches the wavelength, is attenuated if the wave continues to pass on either side of the column, as with the set-up here. If the oscillating water column is $L_{C} \mathrm{~m}$ long with respect to the wavelength then the mean wave height across the side face of the column (for a peak height $H$ ) is given by

$$
\begin{aligned}
\eta(t) & \approx \frac{H}{2} \cos \left(\frac{2 \pi}{T} t\right) \times \frac{1}{\theta} \int_{-\theta / 2}^{\theta / 2} \cos (\phi) d \phi \\
& =\frac{H}{2} \cos \left(\frac{2 \pi}{T} t\right) \times \frac{2 \sin (\theta / 2)}{\theta}
\end{aligned}
$$

where $\theta=2 \pi \times L_{C} / L$. The wave function [11] inside the column is

$$
\eta_{1}(t) \cong \frac{g \cdot \eta(t) e^{j \omega t}}{g-j 0.04 \cdot \frac{2 \pi}{T} \cdot \frac{A_{1}}{A_{2}}}=\frac{9.8 e^{j \omega t}}{9.8-j \frac{14.96}{T}} \eta(t)
$$

and $g$ is the acceleration due to gravity. This assumes that $A_{l}=$ $2.25 / 3 \mathrm{~m}^{2}$ and $A_{2}=0.0126 \mathrm{~m}^{2}$. If we consider a single column $4.5 \mathrm{~m}$ long then and wave period is $2.4 \mathrm{~s}$ then the wavelength is $8.38 \mathrm{~m} \theta=2 \pi \times 4.5 / 8.38=1.07 \pi$ so that

$$
\eta_{1}(t) \approx \frac{0.59 H}{2} \cos \left(\frac{2 \pi}{T} t\right)=X_{1} \cos \left(\frac{2 \pi}{T} t\right)
$$

This would be the case for a single chamber. For three chambers of $1.5 \mathrm{~m}$ long then implementation of (1) leads to

$$
\eta_{1}(t) \approx \frac{0.95 H}{2} \cos \left(\frac{2 \pi}{T} t\right)=X_{1} \cos \left(\frac{2 \pi}{T} t\right)
$$

However, it was found that the chamber height was attenuated much more than this when three chambers were used. Therefore we can modify (1) using the definitions in Fig. 6 (for $2.4 \mathrm{~s}$ wave period) so that

$$
\begin{aligned}
\eta(t) & \approx \frac{H}{2} \cos \left(\frac{2 \pi}{T} t\right) \\
& \times \frac{1}{L_{C}+2 D}\left[\frac{L_{C}}{\theta} \int_{-\theta / 2}^{\theta / 2} \cos (\phi) d \phi+2 D \cos (\phi)\right] \\
\eta_{1}(t) & \approx \frac{0.74 H}{2} \cos \left(\frac{2 \pi}{T} t\right)=X_{1} \cos \left(\frac{2 \pi}{T} t\right)
\end{aligned}
$$

where $D$ is the depth of the chamber $(0.5 \mathrm{~m})$. Table I gives the wavelengths at investigated wave periods using the calculation methods above.

TABLE I MODIFIED WAVELENGTHS DuE TO DEPTH

\begin{tabular}{|c|c|c|c|}
\hline \multirow{2}{*}{} & \multicolumn{3}{|c|}{ Wave period $T[\mathrm{~s}]$} \\
\cline { 2 - 4 } & 2.4 & 2.8 & 4 \\
\hline Deep water wavelength $L_{o}$ & $8.99 \mathrm{~m}$ & $12.23 \mathrm{~m}$ & $24.96 \mathrm{~m}$ \\
\hline Wave tank wavelength $L$ & $8.38 \mathrm{~m}$ & $11.44 \mathrm{~m}$ & $19.70 \mathrm{~m}$ \\
\hline
\end{tabular}

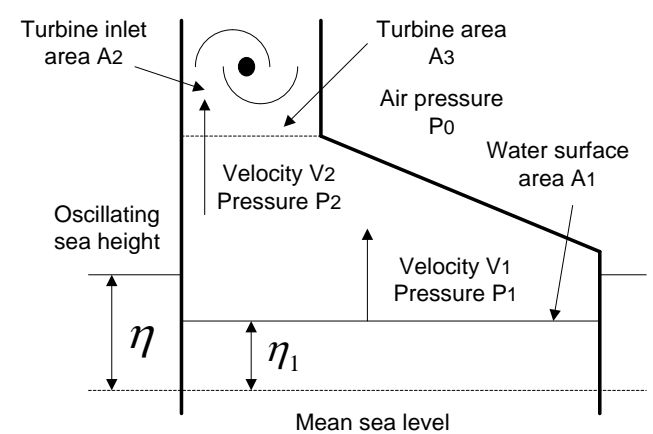

Fig. 5. Definitions of column variables.

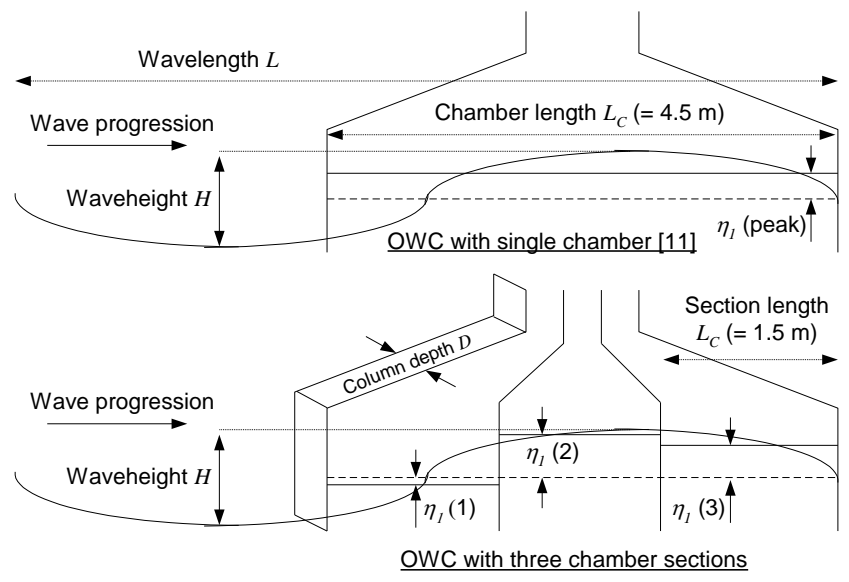

Fig. 6. Full chamber and sectioned chamber arrangements.

The velocities of the water surface inside the column and the turbine inlet can be defined by

$$
V_{2}(t)=\frac{A_{1}}{A_{2}} V_{1}(t)=\frac{A_{1}}{A_{2}} \frac{d \eta_{1}(t)}{d t}
$$

Where $A_{l}$ is the surface area of the water inside one column section $\left(0.5 \times 2.5 \mathrm{~m}^{2}\right), A_{2}$ is the turbine inlet area $(280 \times 95 \div$ $2 \mathrm{~mm}^{2}$ ). We can also define the turbine duct area $A_{3}$ (the complete turbine cross section) as $280 \times 95 \mathrm{~mm}^{2}$. Implementing these equations gives the characteristics for the wave heights as shown in Fig. 6. The inlet velocity was measured using a fan probe with a $70 \mathrm{~mm}$ diameter as discussed earlier. The probe was inserted just below the turbine. The fan was rotated as the airflow changed direction. The probe was located close to the turbine. It was a low inertia device which freewheeled easily so that when put into an alternating airflow it should measure close to the peak air velocity. In addition, it was close enough to the turbine such that it is probably not measuring either $V_{2}$ or $V_{3}$ (Fig. 5); but rather the mean of these two values. Therefore it was concluded that the turbine peak inlet velocity was related to the probe measurement by the equation

$$
V_{2}(\text { peak })=\frac{A_{2}+A_{3}}{2 A_{2}} V_{\text {probe }}(\text { measurement })
$$

The results for the measurements can be compared to the simulations based on equations (2) to (6) as shown in Fig. 7. The idealized characteristics simply represented the case were the water oscillate in phase with the wave height with no 
attenuation due to (2) or (5) and it can be clearly seen that there is a difference and the internal water heights inside the column are reduced compared to the wave heights.

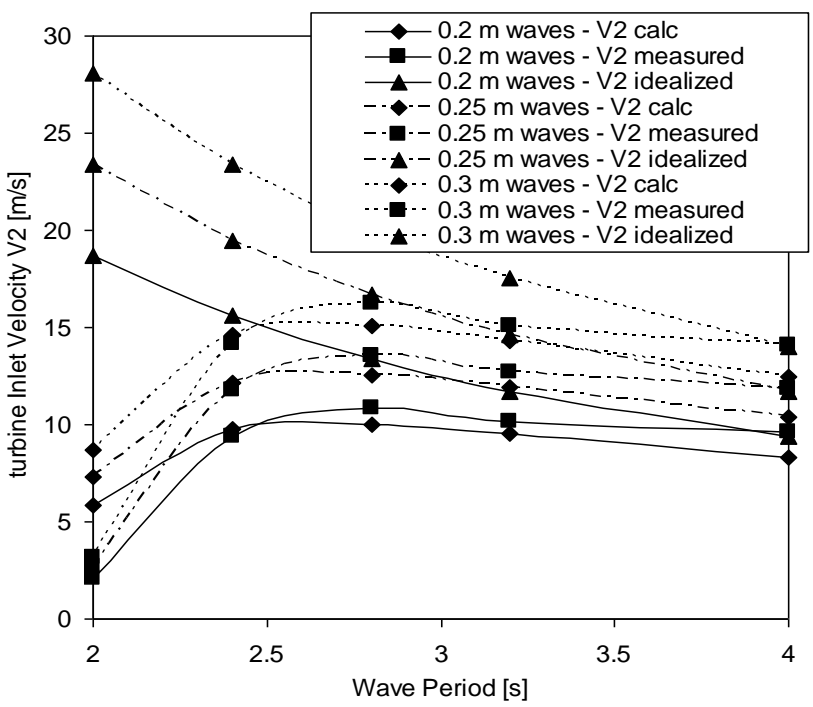

Fig. 7. Simulations against measurement for turbine inlet velocity.

\section{EXPERIMENTAL INVESTIGATION}

In this section we will look at the power available at the turbine then the measured turbine conversion rate based on the velocities measured at the turbine. The overall conversion rate of the system will then be considered and the electrical generation system outlined.

\section{A. Power available at the turbine}

The inlet power can be described using the equation [8]:

$$
\begin{aligned}
& P_{\text {in }}=P_{t}+P_{a} \\
& \left.=\left\{\begin{array}{l}
\rho \frac{A_{1}}{A_{2}}\left[-\frac{(H \omega)^{2}}{4}\left(2 \cos (\omega t)^{2}-1\right)\right] \\
+\rho \frac{Q}{A_{2}}\left(V_{2}-V_{1}\right)
\end{array}\right\}+\frac{1}{2} \rho V_{2}^{2}\right\} Q
\end{aligned}
$$

where the equation of continuity is

$$
Q=V_{1} \times A_{1}=V_{2} \times A_{2}
$$

and $\rho$ is the density of water. The characteristic for (9) when the period is $2.4 \mathrm{~s}$ and the wave height is $0.2 \mathrm{~m}$ is shown in Fig. 8. The mean power is $25.8 \mathrm{~W}$.

Applying to the wave using the values for $V_{2}$ velocities given in Fig. 7 leads to the turbine inlet powers given in Fig. 9. The $2 \mathrm{~s}$ characteristic is ignored since this was not used for performance testing.

\section{B. turbine Performance}

The turbine was connected to a brushless DC machine which was, in turn, connected to an electronic load through a diode bridge rectifier (as discussed earlier). There was a variation of the turbine speed of about $\pm 10 \%$ and the mean speeds were noted together with the mean power delivery.

Space constraints prevent a full description of the electrical system in this digest although it will be thoroughly described in the full paper. However, it should be noted that the system was characterized by mounting the machine against a calibrated drive and torque transducer and the different load conditions repeated in order to calibrate the input torque for the different loadings. Hence it was possible obtain turbine output torques.

Fig. 10 shows the turbine output power for the wave periods of $2.4 \mathrm{~s}, 2.8 \mathrm{~s}$ and $3.2 \mathrm{~s}$. This shows best performance at $2.8 \mathrm{~s}$ with a peak output power of about $25 \mathrm{~W}$.

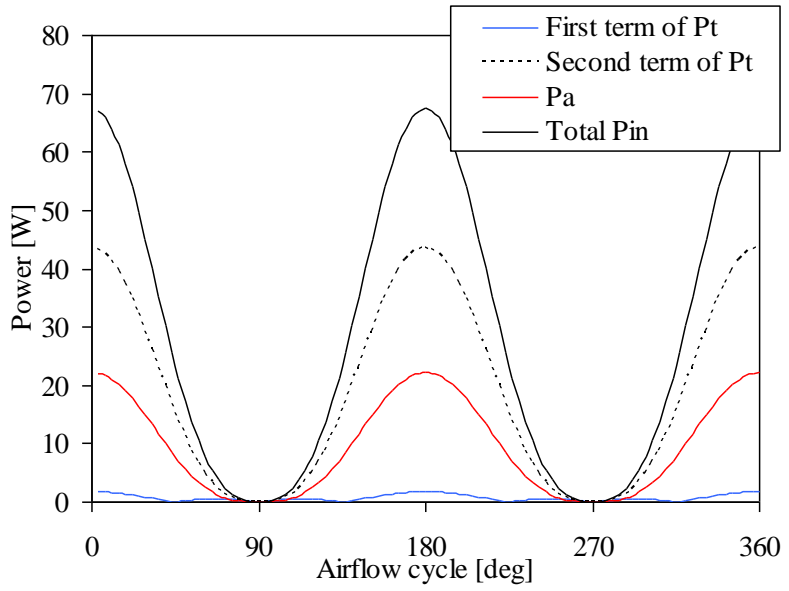

Fig. 8. Input power variation of turbine for $2.4 \mathrm{~s}, 0.2 \mathrm{~m}$ wave.

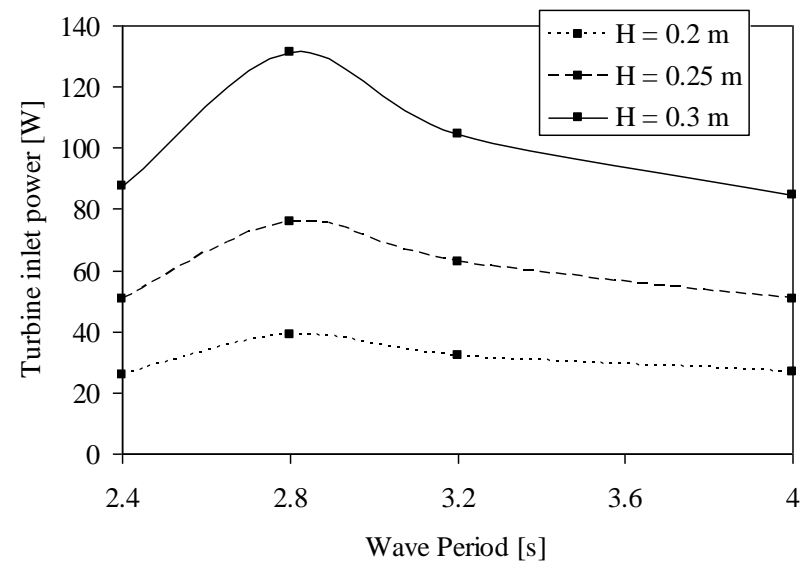

Fig. 9. Power available at turbine inlet (using measured velocities).

Using the turbine inlet power in Fig. 9 we can obtain the conversion factor for the turbine. These are shown in Fig. 11. It can be seen that there is a consistent peak of about $20 \%$. It has been reported that the Savonius rotor can give conversion rates of the order of $25 \%$. With improved ductwork, and the variation of the speed with airflow (so that the turbine speed can track the airflow velocity to a degree) then it is quite reasonable to suggest that $20 \%$ conversion can be obtained. In [8], with a fixed speed and peak conversion of $20 \%$, the conversion was found to be about $15 \%$ when the airflow oscillated (and there was no duct work around the turbine).

Airflow measurement through the turbine using instantaneous anemometry would give a refinement of the calculation which, as previously mentioned, will be the focus of further work. 


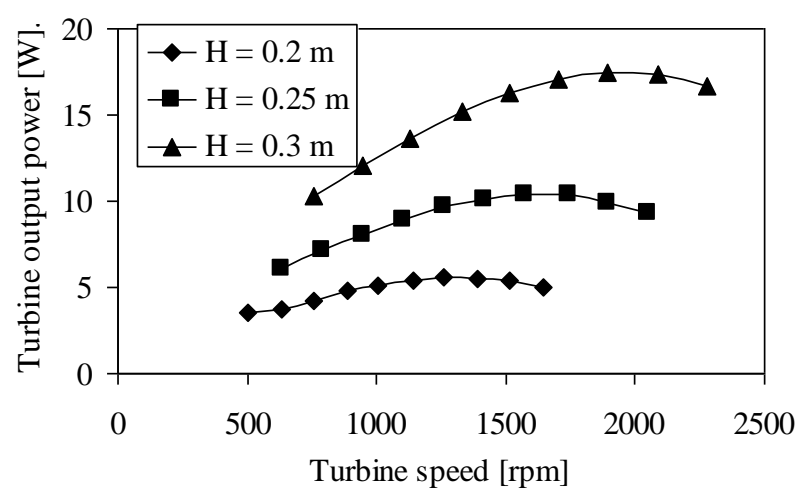

(a) Wave period $=2.4 \mathrm{~s}$

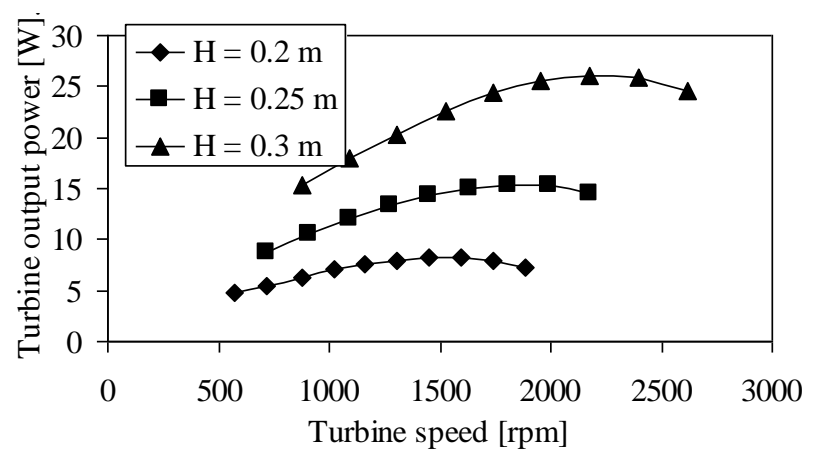

(b) Wave period $=2.8 \mathrm{~s}$

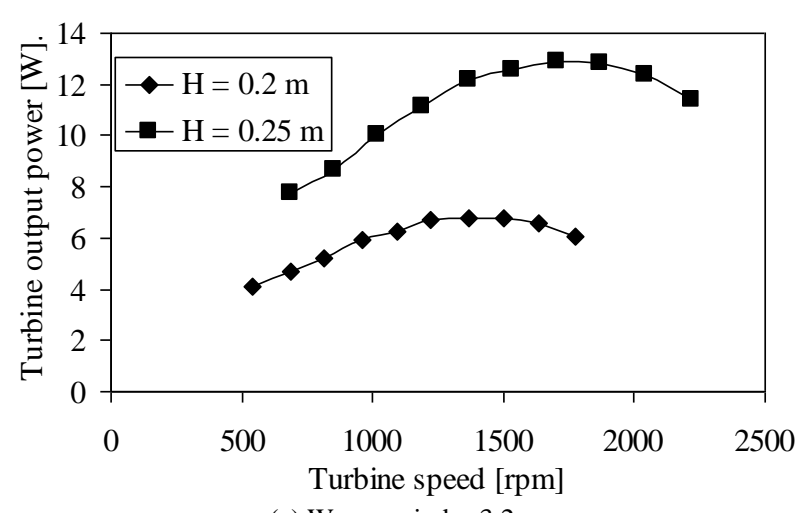

(c) Wave period $=3.2 \mathrm{~s}$

Fig. 10. Output power against speed for different wave periods and heights.

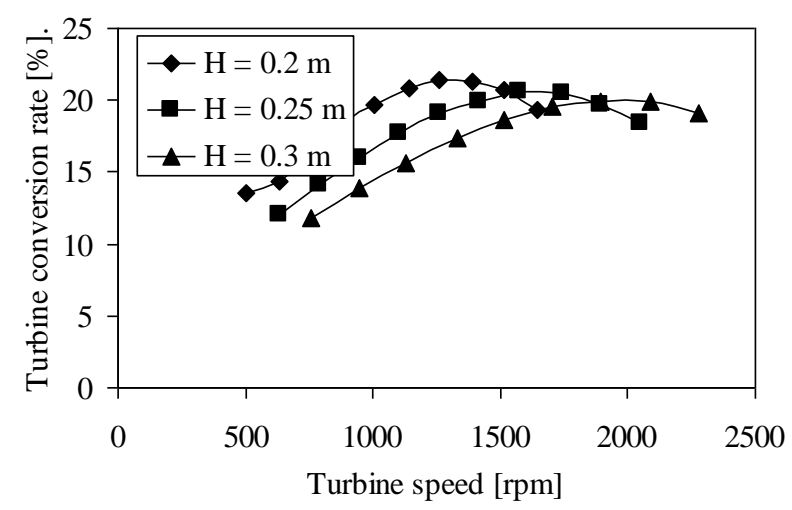

(a) Wave period $=2.4 \mathrm{~s}$

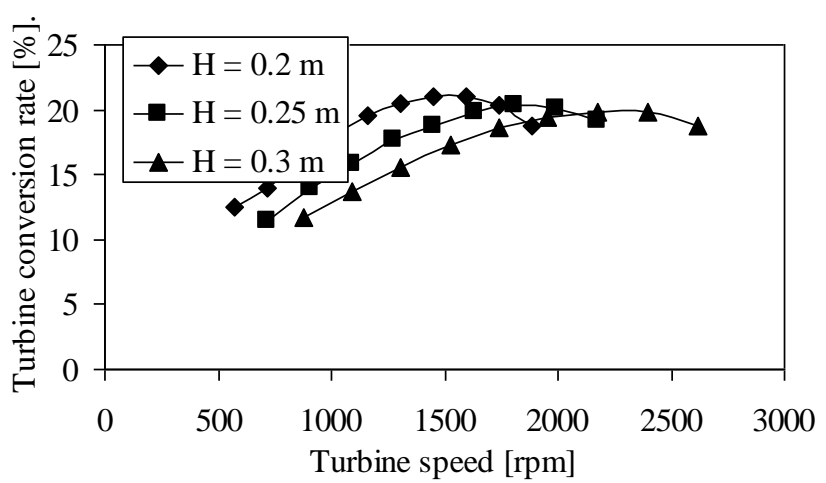

(b) Wave period $=2.8 \mathrm{~s}$

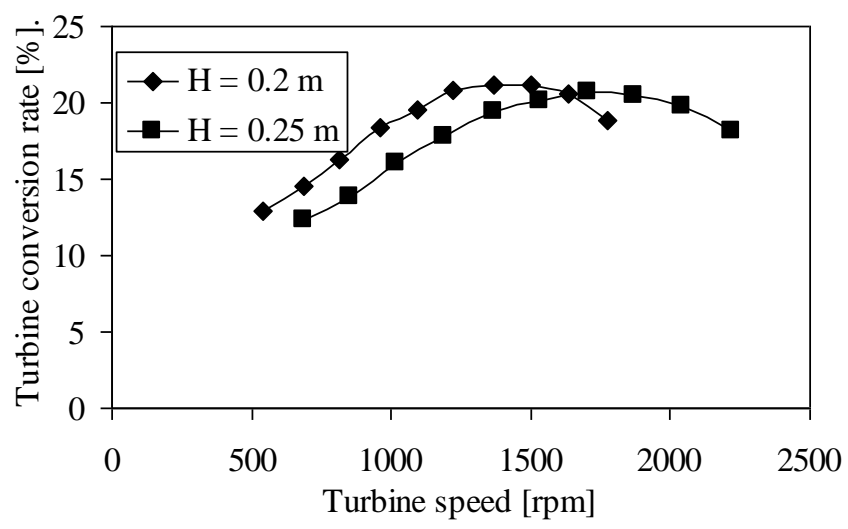

(c) Wave period $=3.2 \mathrm{~s}$

Fig. 11. Turbine conversion rate against speed for different wave periods and heights.

\section{Tip speed ratio}

The mean tip speed ratio can be investigated. If the mean of the inlet velocities $\left(2 V_{2} / \pi\right)$ are used then the mean tip speed ratio (turbine blade tip velocity/ mean inlet velocity) characteristics are shown in Fig. 12. This is only for the $2.8 \mathrm{~s}$ wave periods and it can be clearly seen that the peak conversion factor occurs at a ratio of just over one. The literature suggests that this is correct. The other wave periods produce similar performance characteristics.

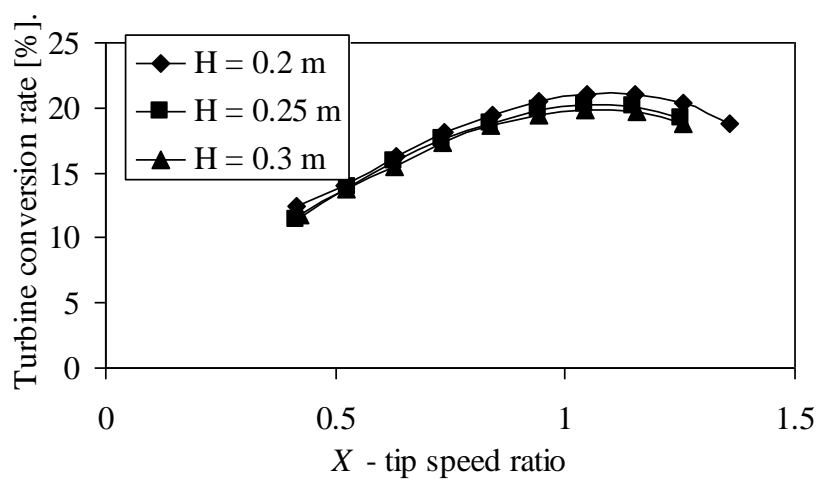

Fig. 12. Mean tip speed ratio at $\mathrm{T}=2.8 \mathrm{~s}$ wave period against conversion factor.

\section{Overall conversion factor}

This is a difficult issue to discuss because the chamber tends to draw in waves as they pass. It is not unusual for buoy 
type of devices to be quoted with conversion factors higher than one. This is because the input power is usually defined as the watts per meter of wave front $\times$ device width to oncoming waves which can lead to devices having conversion factors greater than unity because they draw in wave energy from around. Using the standard equation, where the power per unit of wave front is

$$
P=\frac{\sigma g^{2} H^{2}}{32 \pi f}=\frac{981.2 H^{2}}{f}=981.2 H^{2} T \quad \mathrm{~W} / \mathrm{m}
$$

then for a $0.3 \mathrm{~m}$ wave at $2.8 \mathrm{~s}$ the power is $247 \mathrm{~W} / \mathrm{m}$. Strictly speaking the device has a width of $0.5 \mathrm{~m}$ to oncoming waves which gives a conversion factor of $25 / 123.5=20.2 \%$ which is remarkably close to the turbine conversion factor. This is probably coincidence.

\section{CONCLUSION}

In this paper a segmented oscillating column of a small design using cascaded Savonius rotors at the turbines has been described. It is shown to operate with conversion rates up to $20 \%$ which is excellent for a small scale device.

The performance of the system was put forward in the paper. Further work will be to scaling up of the system and refinement of the instrumentation and control. In this system the air-flow can be considered as more as an estimate and the system control is quite simple, using an electronic resistive load on a brushless permanent magnet machine. However, using basic design algorithms (as described here, and in [8] and [11]) a system can be designed in a straightforward manner.

\section{ACKNOWLEDGMENT}

The authors would like to thank The National Cheng Kung University for support of this work.

\section{REFERENCES}

[1] M.J. Tucker and E.G. Pitt, Waves in Ocean Engineering, Elsevier Publishers, Ocean Engineering Series, 2001.

[2] R. Shaw, Wave Energy: A design challenge, Ellis Horwood Publishers, 1982.

[3] M. E. McCormick, Ocean Energy conversion, John Wiley \& Sons Publishers, New York, 1981.

[4] J. R. Halliday and D. G. Dorrell, "Review of Wave Energy Resource and Wave generator Developments in the UK and the Rest of the World", IASTED EuroPES conference, Rhodes, Greece, 28-30 June 2004 (on CD).

[5] A. Clement, P. McCullen, A. Falcao, A. Fiorentino, F. Gardner, K. Hammarlund, G. Lemonis, T. Lewis, K. Nielsen, S. Petroncini, M.-T. Pontes, P. Schild, B.-O. Sjostrom, H.C. Sorensenaan and T. Thorpe., "Wave Energy in Europe: current status and perspectives", Renewable and Sustainable Energy Reviews Vol. 6, Elsevier Science Publishers, pp 405-431, 2002.

[6] T. Setogushi and M. Takao, "Current status of self rectifying air turbines for wave energy conversion", Energy Conversion and Management, Vol. 47, pp 2382-2396, 2006.

[7] D. G. Dorrell and W. Fillet, "Investigation of a Small-Scale Segmented Oscillating Water Column Utilizing a Savonius Rotor Turbine", International Conference on Energy and Environment ICEE 2006, Kuching, Sarawak, Malaysia, 28-30 August 2006.

[8] D. G. Dorrell, M.-F. Hsieh and W. Fillet, "Segmented small oscillating water columns using in-line Savonius rotors", International Society of Offshore and Polar Engineering Conference, ISOPE 2007, Lisbon, July 2007.

[9] A. Hiramoto, "The Theoretical analysis of an air turbine generation system", Proc Wave and Tidal Energy International Symposium, Canterbury, England, Sept. 27-29, 1978, Vol 1. pp 73-84.

[10] M. C. Percival, P. S. Leung and P. K. Datta, "The development of a vertical turbine for domestic electricity generation", European Wind Energy Conference, 22-25 Nov., London, 2004 (available on line).

[11] D. G. Dorrell and M.-F. Hsieh, "Performance of Wells Turbines for Use in Small-Scale Oscillating Water Columns", International Society of Offshore and Polar Engineering Conference, ISOPE 2008, Vancouver, July 2008 . 